\title{
Haemophagocytic Lymphohistiocytosis: A Case Report and Short Overview
}

\author{
Hossain MA ${ }^{1}$, Akther ${ }^{2}$, Sarkar MA ${ }^{3}$, Paul A ${ }^{4}$, Zannat T ${ }^{5}$, Rifat SM$^{6}$, Shahiduzzaman GKM ${ }^{7}$
}

Conflict of Interest: None
Received: $11-03-2018$
Accepted: $08-05-2018$
www.banglajol.info/index.php/JSSMC

Key Words:

Hemophagocyticlymphohistocytosis (HLH).

\begin{abstract}
Haemophogocyticlymphohistiocytosis (HLH) is a rare but potentially fatal disease, which describes a clinical syndrome of hyper-inflammation resulting in uncontrolled and ineffective immune response. It appears commonly in infancy, although it has been seen in all age groups. A vast majority of cases are acquired due to secondary causes (infections, autoimmune, malignancy, metabolic disorders) but primary HLH (genetic) is also not uncommon which also gets triggered by infection as suggested by recent studies. "Hypercytokinemia" which is the hallmark of HLH can result in end organ damage and even death in some cases if there is delay in diagnosis. The pathological hallmark of this syndrome is uncontrolled activation of T lymphocytes and macrophages, together with an impaired cytotoxic function of NK cells and CD8+T lymphocytes resulting into massive cytokine release (e.g. interferon-ã, $T N F$-á, Interleukin-6, 8, 10, 12, 18) from this cells and overwhelming inflammation. Lymphocytes and macrophages sometimes with haemophagocytic activity accumulate in bone marrow, spleen, liver or lymph nodes. This disorder is characterized by fever, hepatosplenomegaly, lymphadenopathy, skin rash, cytopenias, hepatitis, coagulopathy, and neurological symptoms. We report a case of $55 \mathrm{yr}$. old male presenting with fever and high colored urine who developed clinical and laboratory findings consistent with diagnosis of HLH according to HLH-2004 guidelines. Unfortunately the patient died despite receiving chemotherapy. HLH has multifaceted clinical presentations with often non-specific signs and symptoms that are often found in other clinical conditions. Early recognition of HLH is critical in initiating therapy early and preventing high mortality resulting from multi-organ failure.
\end{abstract}

[J Shaheed Suhrawardy Med Coll 2018; 10(1): 51-58] DOI: http://dx.doi.org/10.3329/jssmc.v10i1.38905

\section{Introduction:}

Hemophagocytic lymphohistiocytosis (HLH) is an aggressive and life-threatening syndrome of excessive immune activation. ${ }^{1}$ HLH presents as a febrile illness associated with multiple organ involvement. It may be primary or secondary HLH. ${ }^{2}$ Primary HLH is better defined

1. Dr. Md. Amzad Hossain, Assistant Professor, Department of Medicine, ShSMCH.

2. Dr. Tahmina Akther, Medical Officer, Department of Virology, BSMMU

3. Dr. Md. Amran Sarker, Assistant Registrar, Department of Medicine, ShSMCH.

4. Dr. Arunava Paul, Registrar, Department of Medicine, ShSMCH.

5. Dr. Tanzina Zannat, IMO, Depart of Medicine, ShSMCH.

6. Dr. Seikh Mohammad Rifat, MO, Department of Medicine, ShSMCH.

7. Dr. GKM Shahiduzzaman, Professor of Medicine, ShSMCH.

Corresponding author: Dr. GKM Shahiduzzaman, Professor of Medicine, ShSMC. as "genetic" encompassing both the familial hemophagocytic lymphohistiocytosis (FHLH) and also HLH occurring in association with Chediak-Higashi syndrome, Griscelli syndrome type 2 and X-linked lymphoproliferative disorder. FHLH is inherited as an autosomal recessive manner and the incidence is higher in areas where parental consanguinity is common. ${ }^{3}$ About $70 \%$ of the cases present before one year of age but only $10 \%$ are symptomatic in the neonatal period. Secondary HLH can present at any age. It has more variability in severity and outcome, although the clinical picture may be identical to primary HLH. It is seen in the context of infection, underlying autoimmune disorders (where it is often termed Macrophage Activation Syndrome; MAS), some metabolic disorders and malignancy (particularly T-cell lymphomas). ${ }^{2} \mathrm{HLH}$ is reported to occur with a wide variety of infections, including bacterial, viral, protozoal and fungal infections. ${ }^{4}$ Many clinical episodes of primary HLH are also triggered by an acute infection. Herpes viruses, in particular EBV, 
are amongst the most common infections associated with HLH in children and young adults. ${ }^{4} \mathrm{HLH}$ may often mimic infectious illnesses, such as overwhelming bacterialsepsis and leptospirosis ${ }^{5}$ and may also obscure the diagnosis of a precipitating, treatable infectious illness (as reported for visceral leishmaniasis). ${ }^{6} \mathrm{HLH}$ is also seen in association with a number of rheumatic diseases like SLE, systemic onset JIA and Kawasaki disease. ${ }^{7}$ Clinical features are often similar to those in primaryHLH but the preceding high levels of inflammatory markers associated with the underlying diagnosis may blur laboratory findings. The presentation of HLH could be acute or insidious. In order to improve the diagnosis of HLH, the Histiocyte Society published diagnostic guidelines. Fever, hepatosplenomegaly and cytopenias are the cardinal features that should raise a doubt of this condition in the physicians mind. In addition to this, continued deterioration in spite of maximal care will almost confirm the diagnosis. We report a case of HLH in adult in order to illustrate the spectrum of clinical features and to emphasis the importance of prompt diagnosis and initiation of therapy.

\section{Case Report:}

Mr Montaz, 55-year-old, Muslim, male, BMI- $20 \mathrm{~kg} / \mathrm{m}^{2}$, cultivator, not known diabetic and hypertensive hailing from Rajbari had got admitted into Medicine department of Shaheed Suhrawardy Medical College Hospital on $3^{\text {rd }}$ July, 2017 with the complaints of high grade remittent fever for one and half months, highest recorded temperature was $105^{\circ} \mathrm{F}$ and high coloururine for same duration which was orange to red in colour amounting to 1.5 to 2 Liters per day associated with occasional dysuria for same duration. He also complained of oral white curd like multiple spots involving inner chick and tongue including dysphagia for the last 1 month. He also gave history of significant weight loss (about $15 \mathrm{~kg}$ ) during the period of his illness. He had H/O repeated exposure to insecticide during farming. He also gave history of occasional extramarital sexual exposure. He had no history of skin rash, headache, convulsion, vomiting, diarrhoea, cough, sore throat, hematemesis, melaena, no stigmata of chronic liver disease, no bleeding manifestation and no significant travel history.

General examination revealed: severe anaemia, mild jaundice, temperature- $104^{\circ} \mathrm{F}$, and pulse- $108 \mathrm{~b} / \mathrm{min}, \mathrm{BP}: 90$ / $55 \mathrm{mmHg}$, Respiratory rate: 18 breaths/min, Peripheral lymph nodes: not palpable. All other parameters were within normal limit. Systemic examination revealed: Oral candidiasis, splenomegaly (18cm enlarged), hepatomegaly
( $3 \mathrm{~cm}$ enlarged). Other systemic examinations revealed no abnormality.

Investigations revealed: hemoglobin $4.8 \mathrm{~g} / \mathrm{dL}$, leukocytes $5500 / \mathrm{mm}^{3}$ with $62 \%$ neutrophils, platelets $2,00,000 / \mathrm{mm}^{3}$, microcytic hypochromic anemia in PBF, negative malarial parasite, $5.61 \%$ reticulocyte count; Urine R/M/E: albumin $(1+)$; blood and urine culture: no organism in both aerobic and anaerobic culture; ICT for Malaria and Kala-azar were negative; VDRL: negative; Viral markers (HBSAg, AntiHCV, Anti-HIV1 and HIV2): negative; CXR: no radiological abnormality; ECG: within normal limits; USG of whole abdomen: moderate splenomegaly and mild hepatomegaly; S. creatinine: $1.2 \mathrm{mg} / \mathrm{dl}$, S. electrolytes: normal; S. bilirubin: 4.69 mg/dl, SGPT: 19 U/L; RBS: 6.8 $\mathrm{mmol} / \mathrm{L}$; coombs test: direct- weakly positive, indirectnegative, hemoglobin electrophoresis: normal; febrile antigen: negative, MT- negative, ANA- negative, endoscopy of upper GIT: Peptic ulcer disease; urine DGI microscopy: no leptospira, S. Albumin: $2.42 \mathrm{Gm} / \mathrm{dl}$, S. triglyceride: $480 \mathrm{mg} / \mathrm{dl}$, S. Ferritin: $15800 \mathrm{ug} / \mathrm{L}$.

During in- hospital course of illness, the patient received empirically injectable broad-spectrum antibiotics (including meropenem) along with multiple PRBCs. Despite of supportive treatment the patient continued to remain febrile and there was progressive deterioration of general condition. At this stage with precaution and supportive care, bone marrow aspiration was done which revealed as hyper cellularity, $\mathrm{M} / \mathrm{E}$ ratio decreased with hyperactive erythropoiesis with micronormoblastic and megaloid changes, granulopoiesis relatively depressed and maturing into segmented form. Megakaryocytes were normal. Lymphocytes and plasma cells were normal and also showed significant numbers of haemophagocytes altogether suggestive of Haemophagocytic-lymphohistocytosis (HLH), Fig: 1.

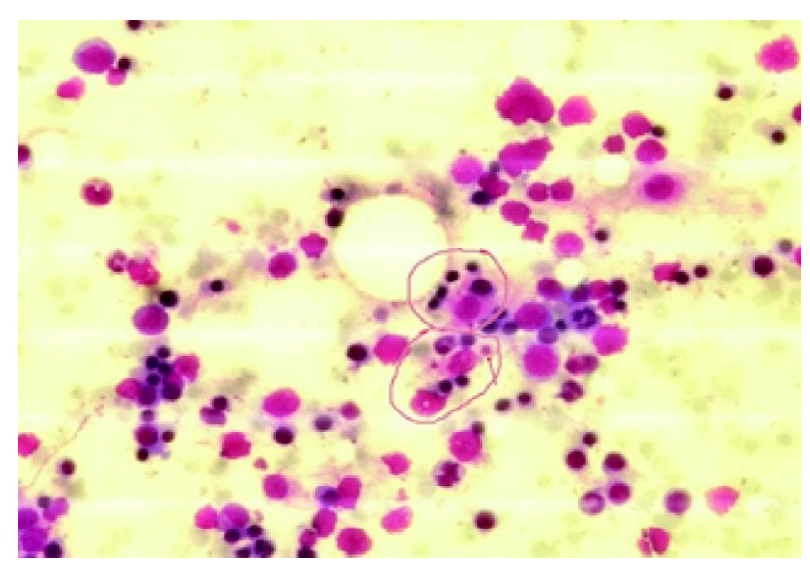

Fig.-1: Bone marrow smears showing multiple haemophagocytic cells. 
Patient fulfilled five of eight diagnostic criteria of HLH including fever, splenomegaly, high ferritin, hypertriglyceridaemia and typical bone marrow findings. Therefore according to HLH-2004 protocol treatment was initiated with Etoposide, Dexamethasone and Cyclosporine A. Patient remained static during initial three days of chemotherapy but subsequently clinical and biochemical parameters deteriorated with all continued supportive treatments. The clinical condition of the patient further deteriorated with circulatory \& respiratory insufficiency requiring inotropic support and mechanical ventilation. Despite continued specific and supportive therapy, the patient died on $27^{\text {th }}$ July 2017 .

\section{Discussion:}

HLH encompasses a heterogeneous class of rare but potentially fatal disorders characterized by multi-system inflammation, that occurs due to prolonged and intense activation of antigen- presenting cells (macrophages, histiocytes) and CD8+T-cells, and excessive proliferation and ectopic migration of $\mathrm{T}$-cells ${ }^{8}$ resulting into consumption and apoptosis of various hematologic cell lines. The primary form (FHLH) is an inflammatory disease, which is similar to secondary one on the basis of symptoms. Age of onset of this variety is less than one year of age in $70 \%$ of cases but it can rarely be observed in the first two weeks of life. ${ }^{4}$ In rare cases, it may occur in adults as well. Although several types of gene mutations e.g.; PRF 1, UNC 13D, STX 11,RAB27A, STXBP2, $S H 2 D 1 A, X I A P, L Y S T$ etc. have been identified in patients with primary $\mathrm{HLH}^{1,9}$ they all lead to the common phenotype of impaired cytotoxic function by NK and T cells, and a predisposition to develop HLH.

Acquired (secondary) forms of HLH may develop as a result of strong immunological activation of the immune system, which may be caused by severe infections, rheumatologic disorders and malignancies. It generally occurs among older children and adults who present without a family history or known genetic cause. Leading triggering agents of infection-associated haemophagocytic syndrome (IAHS) are viruses of the herpes group, especially EBV ${ }^{10}$ and $C M V .{ }^{11}$ The patients in the original report by Risdallet al. were mostly associated with viral infection following organ transplantation. ${ }^{12}$ Subsequently its association was established with many viruses as well as a number of bacteria, fungi, mycobacteria and parasite and the term Viral Associated Haemophagocytic Syndrome (VAHS) was redesigned as Infection Associated Haemophagocytic Syndrome (IAHS). A review of published cases in children with IAHS reported that more than half of them were from Far East and Epstein Barr Virus (EBV) was the triggering virus in $74 \%$ of the children ${ }^{4}$.
Fardetet al reported Human Herpes virus 8 associated HLH among HIV-infected patients. ${ }^{13}$ Malignancy associated acquired HLH (MAHS), with lymphoma being the commonest trigger, is well known entity in adults but rare in children. In a recent review of patients with lymphoma associated haemophagocytic syndrome (LAHS) in Japan showed that EBV genome was detected from more than $80 \%$ of T/NK cell lymphoma but rarely from B cell lymphoma. ${ }^{14}$ Macrophage activation syndrome (MAS) is a special form of HLH which occurs both in children and adults with autoimmune diseases, ${ }^{15}$ and most commonly seen in association with systemic onset juvenile rheumatoid arthritis (sJRA) or adult onset Still's disease and rarely found with systemic lupus erythematosus or other entities. Clinical picture and laboratory findings are similar to HLH. Patients of sJRA were found to have low NK cell function and perforin expression compared to other form of rheumatoid arthritis. MAS are a grave disorder with a mortality of about $10-20 \%$. It has been suggested by some rheumatologists that MAS be classified as a form of secondary HLH.

Categorizing patients as having either "primary" or "secondary" HLH at diagnosis is of limited value. Without a known genetic defect or family history, it is often not possible to make an initial diagnosis of "primary" or "secondary" HLH. Furthermore, a careful search for underlying disease triggers should be performed in all patients. However, recurrence of HLH, in the absence of autoimmune disease or malignancy, is generally considered to be good evidence that a patient has primary HLH. Despite attempts to differentiate primary from secondary $\mathrm{HLH}$, the clinical presentation is highly overlapping, hence initial treatment should not be delayed or altered based on these categories. The clinical picture of HLH is nonspecific and differentiation of HLH from sepsis with disseminated intra vascular coagulation (DIC) can be difficult. Generally, the onset of HLH is acute or sub-acute, with persistent high-grade fever, anorexia, and weight loss. Enlargement of the spleen and liver are often seen in HLH. Rash, jaundice, edema, lymphadenopathy, and cerebromeningeal symptoms (meningitis, seizures, gait and balance problems, etc.) ${ }^{16}$ can also be present. Life threatening multi organ failure is frequently seen in fullpictured HLH. The fever often fluctuates with complete remission and recurrence. Patients may have a variety of skin manifestations, including generalized maculopapular erythematous rashes, generalized erythroderma, edema, panniculitis, morbilliform erythema, petechiae, and purpura. ${ }^{17}$ The incidence of skin manifestations ranges from $6 \%-65 \%$ with highly pleomorphic presentations. Some patients may present with features suggestive of Kawasaki 
disease, including erythematous rashes, conjunctivitis, red lips, and enlarged cervical lymph nodes. ${ }^{18}$

Patients may develop pulmonary dysfunction, which is an ominous sign. Our patient developed acute respiratory failure and needed ICU support including mechanical ventilation. More than one-third of patients will present with neurologic symptoms, including seizures, meningism, altered level of consciousness, cranial nerve palsy, psychomotor retardation, ataxia, irritability, or hypotonia. ${ }^{16}$ Patient may have even only neurological manifestations. The cerebrospinal fluid (CSF) is abnormal in $>50 \%$ of HLH patients with findings of pleocytosis, elevated protein, and/or haemophagocytosis. MRI findings are variable, including discrete lesions, leptomeningeal enhancement, or global edema, and images correlate with neurologic symptoms. ${ }^{19}$ Retinal hemorrhages, swelling of the optic disc and infiltration of the choroid have been reported in infants with HLH. ${ }^{20}$ Diffuse peripheral neuropathy with pain and weakness secondary to myelin destruction by macrophages may also occur. The workup for HLH includes a complete and differential blood count, renal function tests, liver function tests, fasting triglycerides, international normalized ratio, partial thromboplastin time, fibrinogen, and ferritin. The most characteristic laboratory findings in HLH are cytopenia affecting at least 2 cell lineages in peripheral blood and hyperferritinemia, often "sky high" $>10,000 \mu \mathrm{g} / \mathrm{L} \cdot{ }^{21}$ Anemia and thrombocytopenia occur in $>80 \%$ of patients at the time of presentation ${ }^{21}$, that depends on combination of haemophagocytosis, hypersplenism and massive cytokine release by activated macrophages (e.g, INF- $\alpha$, TNF- $\alpha$ ). ${ }^{22}$ Thrombocytopenia is almost always present and can lead to severe bleeding, especially in the presence of coagulopathy (e.g. low fibrinogen level). Hepatic manifestations of HLH include a moderate increase in serum transaminases, pronounced cholestasis, raised serum bilirubin, decreased serum albumin and coagulation factors deficiency. ${ }^{23}$ Most patients have variable evidence of hepatitis at presentation. Autopsy evaluation study of the liver has shown chronic persistent hepatitis with periportal lymphocytic infiltration in 22 of 27 patients with HLH. ${ }^{24}$ Hypertriglyceridemia, hypofibrinogenemia, elevated serum lactate dehydrogenase, hyponatremia are frequently seen in HLH. Elevated VLDL and decreased HDL may also be present. ${ }^{24}$ Nearly $95 \%$ of patients have features of disseminated intravascular coagulation and are at high risk for acute bleeding ${ }^{25} \&$ associated with high ( $>70 \%$ ) mortality when present. Elevated ferritin levels $(>10,000 \mathrm{ig} / \mathrm{L})$ are reported to be $90 \%$ sensitive and $96 \%$ specific for HLH in children. ${ }^{26}$ although this has not been validated in adults.
Investigations for secondary triggers of HLH include investigations for viral infections (particularly EBV, HSV, HIV and CMV) and for malignancies as clinically indicated. A search for these etiologic agents was performed in our patient. However it should be emphasized that with the possible exception of leishmaniasis, anti-infectious therapy alone is not sufficient to control HLH. A lumbar puncture is also recommended as part of a diagnostic workup, and more than half of patients will have a moderate pleocytosis and/or increased protein content, even in the absence of neurological symptoms. The caution with lumbar puncture must be taken with regard to apossibly increased intracranial pressure.

All patients should have a bone marrow aspiration. However, frank haemophagocytosis may not be observed early in the course of the disease, and serial marrow aspirates may be helpful. Haemophagocytosis might be found in the first bone marrow aspiration of a FHLH patient but the absence of it will not rule out this diagnosis. As a result, if the bone marrow is not conclusive, material should be obtained from other organs e.g.; liver, spleen, and lymph nodes and occasionally the central nervous system, skin and serial aspirates over time may also be helpful. In our case, the bone marrow aspiration was performed and it revealed haemophagocytosis. Activated macrophages may engulf erythrocytes, leukocytes, and platelets, their precursors, and cellular fragments. Although haemophagocytosis in bone marrow is associated with HLH, the morphologic phenomenon may also be induced by more common events, including blood transfusions, infection, autoimmune disease, and other forms of bone marrow failure or causes of red blood cell destruction. Despite the nomenclature of HLH, diagnosis should never be made or excluded solely on the presence or absence of haemophagocytosis. Infiltration of bone marrow or liver by activated macrophages, along with global clinical evaluation, may distinguish HLH from other causes of haemophagocytosis. Two highly sensitive diagnostic parameters are low natural killer (NK) cell activity 27,28,29 and a hypercytokinemia, in particular elevated alpha chain of the soluble interleukin-2 receptor (sIL-2r, sCD25) in serum $^{30,31}$ and in the CSF. ${ }^{31,32}$

NK cell activity helps to differentiate between reactive forms of HLH from familial type. In patients with FHLH, NK cell number is normal, but the activity is persistently decreased or absent. Patients with acquired HLH may have low NK cell number; NK cell function is decreased with active disease, but usually reverts to normal after treatment. ${ }^{21}$ The laboratory workup should involve perforin expression by NK cell by using flow cytometry. Patients lacking perforin expression should be analyzed 
for the PRFI gene mutation. Molecular studies for HLH include mutations in perforin (PRF), Munc (UNC13D), syntaxin 11(STX11) and others can be done at specialized centers.

To assist with the rapid diagnosis of HLH, the Histiocyte Society has developed a set of diagnostic guidelines that encompass both clinical which are summarized in Table- $1 .{ }^{33}$

\section{Table 1}

Molecular diagnosis compatible with hemophagocyticlymphohistiocytosis ${ }^{33}$

At least five out of the eight following criteria are needed for diagnosis of HLH.

1. Fever

2. Splenomegaly

3. Cytopenia (involving at least two lineage in the peripheral blood film)

Hemoglobin $<9 \mathrm{~g} / \mathrm{dL}$ or $<10 \mathrm{~g} / \mathrm{dL}$ in newborn babies Platelets $<100 \times 10^{9} / \mathrm{L}$

Neutrophils $<1.0 \times 10^{9} / \mathrm{L}$

4. Hypertriglycerides $(>265 \mathrm{mg} / \mathrm{dL})$ or hypofibrinogenemia $(<150 \mathrm{mg} / \mathrm{dL})$

5. Documentedhemophagocytosis in a bone marrow, liver or node biopsy

6. Decreased or absent NK-cell activity

7. Elevated ferritin $>500 \mathrm{ug} / \mathrm{L}$

8. Elevated soluble IL-2 receptor alpha $(>2400 \mathrm{U} / \mathrm{mL})$

N.B: In the absence of family history or specific molecular diagnosis, at least five diagnostic criteria are needed for a diagnosis of HLH.

In the absence of a family history or specific molecular diagnosis, an assemblage of at least five of the eight diagnostic criteria are needed for a diagnosis of HLH and initiation of therapy. ${ }^{33}$ At the end after ruling out other diagnoses and considering the fact that our patient had five criteria for HLH (fever, splenomegaly, hyperferritinemia, hypertriglyceridaemia and haemophagocytosis in bone marrow), we decided that HLH is the most probable diagnosis. It is important to consider the fact that none of these eight criteria are specific for HLH diagnosis and might be found in sepsis, SIRS and MODS. 34,35,36 For example the etiology of hypertriglyceridemia in these states can be multifactorial such as insulin resistance ${ }^{37,38}$ and inhibition of lipoprotein lipase activity 39,40 . High level of serum ferritin has also been associated with inflammatory states and is frequently seen in toxic patients due to the up regulation of hemoxygenase-1 (heat shock protein). ${ }^{41,42}$ Ferritin is also an anti-apoptotic agent in ischemia-reperfusion injury ${ }^{43}$. Elevated soluble IL-2 receptor (CD25) is also observed in sepsis, SIRS and can be a predictive marker in neonatal sepsis. ${ }^{44,45}$ Similar to HLH disease, NK-cell activity is also decreased in sepsis and thermal injury. ${ }^{46}$

The therapy of any form of HLH should focus on: (1) suppression of the life-threatening hyper-inflammatory status by destruction of activated CD8+T lymphocytes and macrophages, and (2) treatment of any existing HLH triggers. $22,33,47$ In cases of FHL, an additional aim is correction of the underlying immune defect. ${ }^{22,33,48}$ The first prospective international treatment protocol for $\mathrm{HLH}$ (HLH-94) was introduced in $1994 .{ }^{49}$ The experience gained from this protocol and other studies have led to the development of a new treatment protocol, HLH-2004 (including etoposide, dexamethasone and CyA). ${ }^{33}$ Current international HLH 2004 protocol is designed for all patients with newly diagnosed HLH, with or without evidence of familial or genetic disease, and regardless of suspected or documented infection. ${ }^{33}$ The protocol represents systemic chemoimmunotherapy including dexamethasone, cyclosporine A, etoposide and, in selected patients, intrathecal therapy with methotrexate. Corticosteroids show cytotoxic effect and inhibit expression on cytokines. Cyclosporine A prevents T-lymphocyte activation. Etoposide is an anti-neoplastic agent highly effective in monocytic and histiocytic disorders. Intrathecal methotrexate is used only in patients with persistently abnormal cerebrospinal fluid or progressive neurological symptoms and CNS reactivation. ${ }^{33}$

In genetic HLH the ultimate aim must be hematopoietic stem cell transplantation (HSCT) to replace congenitally defective immune system with normal functioning immune effectors cells of healthy donors. However, in the vast majority of FHLH cases immuno-chemotherapy with HLH94 or HLH-2004 protocols is temporarily effective in the control of disease, and the outcome of FHLH is uniformly fatal unless the patient undergoes allogeneic stem cell transplantation (allo-SCT). ${ }^{33,50,51}$ Treatment of sHLH is not standardized so far and remains highly variable across the centers. Obviously, if possible, treatment of any existing trigger of HLH is a must. Front line treatment of infection associated HLH and MAS (particularly of milder grades) usually involves corticosteroids (as in HLH-94 and HLH-2004 protocols) with or without intravenous immunoglobulin (IVIG), which may be sufficient to control hyperinflammation. ${ }^{22}$ After improvement of complete blood count and resolution of coagulopathy, steroids are slowly 
tapered down to avoid relapses. ${ }^{22}$ Patients with viral associated haemophagocytic syndrome should receive appropriate anti-viral therapy such as ganciclovir for CMV. Other interventions include supportive therapy with antimicrobial prophylaxis and intravenous immunoglobulins (IVIg). ${ }^{33,52}$ Emmenegger and others had evidence that IVIG is effective in the treatment of HLH. ${ }^{53}$ A key finding of their analysis was that efficacy of IVIG was satisfactory if administered at the beginning (within hours) of the macrophage activation process. Rituximab, an anti-CD20 monoclonal antibody, has been used to suppress EBV-infected B cells in HLH. ${ }^{54}$ The utility of biological response modifiers, such as TNF- $\alpha$ inhibitors, IL-1 inhibitors, IL-6 inhibitors or anti-CD52 antibodies remains unclear. Available case reports have conflicting results, and at present time there is no consensus on recommendations in respect to this group of drugs in HLH. ${ }^{55,56,57,58}$ Finally, anecdotal reports have also shown the efficacy of allo-SCT in refractory or recurrent sHLH (e.g., EBV-HLH, M-HLH). ${ }^{59,60,61,62}$ Acquired HLH, even when treated in a timely manner, can be fatal and deaths being reported among patients treated with massive doses of steroids ${ }^{63}$. However, corticosteroid resistant nonresponders may benefit from second-line therapies, such as CyA. If there is no response to aforementioned drugs, use of the HLH-2004 protocol including etoposide is recommended. ${ }^{22,33}$ In summary, patients with sHLH could be started on therapy without etoposide, as long as treatment adjustments are made rapidly in refractory cases. ${ }^{64}$ Initial treatment is given for eight weeks, and patients with persistent disease or an underlying genetic abnormality (primary HLH) should go on to continuation therapy as a bridge to allogeneic stem cell transplantation. In patients with poor performance status and multi-organ dysfunction, palliation is reasonable.

Although symptoms and laboratory features improve within 2 to 3 weeks, in some cases cytopenia may persist. In these cases bone marrow examination should be repeated to differentiate between non-response and myelosuppression due to etoposide. If there is no response, then unlikely to have benefit with medical treatment. There is no established salvage regimen. Isolated patient has responded to daclizumab, alemtuzumab or to stem cell transplantation. Hasegawa et al reported remission of $\mathrm{HLH}$ after syngeneic bone marrow transplantation. ${ }^{65}$ Despite treatment, the prognosis of both familial and acquired forms of HLH is usually poor and is rapidly fatal in untreated cases. The CNS disease can cause relapses and may results into irreversible disability. Since HLH can be rapidly fatal without specific intervention, it is recommended that treatment be started when there is a high clinical suspicion, even when results of some diagnostic studies are still pending.

\section{Conclusion:}

HLH is a syndrome of uncontrolled immune activation that has become increasingly recognized over the past decade. It can be due to an underlying defect in cytotoxic function or secondary to a trigger, frequently in the setting of immunosuppression or a genetic predisposition. In adults, HLH is often associated with a malignant, infectious, or autoimmune disorder. Early recognition is crucial and without prompt treatment HLH is often fatal. Treatment includes targeting the underlying disorder and controlling the immune dysregulation. Etoposide, dexamethasone, and ultimately HSCT are the mainstay for the majority of patients with HLH. Despite treatment, the prognosis of both familial and acquired forms of HLH is usually poor and is rapidly fatal in untreated cases. Further studies are required to improve our understanding of the optimal treatment of HLH in adults.

\section{Rerefences:}

1. Jordan MB, Allen CE, Weitzman S, Filipovich AH, McClain KL. How I treat haemophagocyticlymphohistiocytosis. Blood. 2011 Oct 13; 118 (15): 4041-52.

2. Chang CS, Wang CH, Su I J, Chen YC, Shen MC. Hematophagichistiocytosis: a clinicopathologic analysis of 23 cases with special reference to the association with peripheral T-cell lymphoma. J Formos Med Assoc 1994; 93:421-8.

3. Janka GE. Familial haemophagocyticlymphohistiocytosis. Eur J Pediatr 1983; 140:221-230.

4. Fisman DN. Haemophagocytic syndromes and infection. Emerg Infect Dis 2000; 6 (6): 601-608.

5. Yang CW, Pan MJ, Wu MS, Chen YM, Tsen YT, Lin CL, et al. Leptospirosis: an ignored cause of acute renal failure in Taiwan. Am J Kidney Dis 1997; 30:840-5.

6. Matzner Y, Behar A, Beeri E, Gunders A, Hershko C. Systemic leishmaniasis mimicking malignant histiocytosis. Cancer 1979; 43:398-402.

7. Wong KF, Hui PK, Chan JK, Chan YW, Ha SY. The acute lupus haemophagocytic syndrome. Ann Intern Med 1991; 114:387-90.

8. Filipovich AH. Haemophagocyticlymphohistocytosis and other haemophagocytic disorders. Immunol Allergy Clin North Am 2008; 28: 293 -313.

9. Lazkowsky p. Hystocytosis syndrome. In: Lazkowsky P. Manual of pediatric hematology \& oncology. $4^{\text {th }}$ ed. Newyork: Academic press 2006: 604-29.

10. Kumar N, Mehta C, Sarma S, and Metha Y. Epstien- barr virus infection- Related haemophagocyticlymphohisticytosis. Indian Journal Crit Care Med. 2015 jul; 19(7): 416-418.

11. Gupta A, Sen R, Batra C, Banerjee D, Gupta A and Jein M. Haemophagocutic syndrome secondary to CMV infection in an infant. J Cytol. 2011 Jan-Mar; 28(1): 36-38.

12. Risdall RJ, McKenna RW, Nesbit ME, et al. Virus associated haemophagocytic syndrome: a benign histiocytic proliferation distinct from malignant histiocytosis. Cancer 1979; 44: 993-1002. 
13. Fardet, L Blum, D. Kerob, F. Agbalika, L. Galicier, A. Dupuy et al. Human Herpes virus 8 associated HaemophagocyticLymphoHistiocytosis in Human Immunodeficiency Virus Infected patients. Clinical Infectious Disease 2003; 37:285-91.

14. Takahashi N, Chubachi A, Miura I, Nakamura S, Miura AB. Lymphoma associated haemophagocyticsyndroms in Japan. RinshoKetsueki 1999; 40:542-9.

15. Deane S, Selmi C, Teuber SS et al. Macrophage activation syndrome in autoimmune disease. Int Arch Allergy Immunol. 2010; 153: 109-120.

16. Horne A, Trottestam H, Arico M, et al. Frequency and spectrum of central nervous system involvement in 193 children with haemophagocyticlymphohistiocytosis. Br J Haematol 2008; 140(3): 327-335.

17. Morrell DS, Pepping MA, Scott JP, Esterly NB, Drolet BA. Cutaneous manifestations of haemophagocyticlymphohistiocytosis. Arch Dermatol 2002; 138(9); 1208-1212.

18. Palazzi DL, McClain KL, Kaplan SL. Haemophagocytic syndrome after Kawasaki disease. Pediatr Infect Dis J 2003; 22(7): 663-666.

19. Goo HW, Weon YC. A spectrum of neuroradiological findings in children with haemophagocyticlymphohistiocytosis. PediatrRadiol 2007; 37(11): 1110-1117.

20. Petersen RA, Kuwabara T. Ocular manifestations of familial lymphohistiocytosis. Arch Ophthalmol 1968; 79(4): 413416.

21. Janka GE. Haemophagocytic Syndromes. Blood Rev 2007; 21: $245-53$

22. Janka G: Haemophagocyticlymphohistiocytosis: When the immune system runs amok. Clin. Padiatr 2009; 221: 278-85

23. De Kerguenec C, Hillaire S, Molinie V, Gardin C, Degott C, Erlinger S, et al. Hepatic manifestations of haemophagocytic syndrome: a study of 30 cases. Am J Gastroenterol 2001; 96(3): $852-7$

24. Ost A, Nilsson-Ardnor S, Henter JI. Autopsy findings in 27 children with haemophagocyticlymphohistiocytosis: Histopathology. 1998 Apr; 32(4): 310-6

25. Takala A, Jousela I, Jansson SE, Olkkola KT, Takkunen O, Orpana A et al. Markers of systemic inflammation predicting organ failure in community-acquired septic shock. ClinSci (Lond) 1999; 97: 529-38.

26. Allen CE, Yu X, Kozinetz CA, McClain KL. Highly elevated ferritin levels and the diagnosis of haemophagocyticlymphohistiocytosis. Pediatr Blood Cancer 2008; 50 (6): 1227-35.

27. Ladisch S, Poplack DG, Holiman B, et al. Immunodeficiency in familial erythrophagocyticlymphohistiocytosis. Lancet 1978; 1: 581-583.

28. Perez N, Virelizier J, Arenzana-Seisdedos F, et al. Impaired natural killer cell activity in lymphohistiocytosis syndrome. J Pediatr 1984; 104: 569-573.

29. Sullivan KE, Delaat CA, Douglas SD, et al. Defective natural killer cell function in patients with haemophagocyticlymphohistiocytosis and in first-degree relatives. Pediatr Res 1998; 44:465-468.

30. Palazzi DL, McClain KL, Kaplan SL. Haemophagocytic syndrome in children: an important diagnostic consideration in fever of unknown origin. Clin Infect Dis 2003; 36(3): 306-31.
31. Schneider EM, Lorenz I, Mu ller-Rosenberger M, et al. Haemophagocyticlymphohistiocytosis (HLH) is associated with deficiencies of cellular cytolysis but normal expression of transcripts relevant to killer cell induced apoptosis. Blood 2002; 100: 2891- 2898 .

32. Komp DM, McNamara J, Buckley P. Elevated soluble interleukin-2 receptor in childhood haemophagocytichistiocytic syndromes. Blood 1989; 73:2128-2132. (

33. Henter JL, Horne A, Arico M et al.: HLH-2004: Diagnostic and therapeutic guidelines for haemophago-cyticlymphohistiocytosis. Pediatr. Blood Cancer 2007; 48: 124-31.

34. Castillo L, Carcillo J. Secondary. Haemophagocytic lymphohistiocytosis and sever sepsis/systemic inflammatory response syndrome/multiorgan dysfunction syndrome/ macrophage activation syndrome share common intermediate phenotypes on a spectrum of inflammation. PediatrCrit Care Med 2009; 10:387-92.

35. Karapinar B, Yilmaz D, Balkan C, Akin M, Ay Y, Kvakli K. An unusual cause of multiple organ dysfunction syndromes in the pediatric intensive care unit: HaemophagocyticLymphohistocytosis. PediatrCrit Care Med; 2009; 10:285- 91 .

36. Gupta A, Tyrrell P, Valani R, Benselar S, Abdelhaleem M, Weitzman S. Experience with haemophago-cyticlymphohistocytosis/ Macrophage activation syndrome at a single institution. J Pediatr HematolOncol 2009; 31: 81-5.

37. Samra JS, Summers LK, Frayn KN. Sepsis and fat metabolism. Br J Surg 1996; 83: 1186-96.

38. Wendel M, Paul R, Heller AR. Lipoproteins in inflammation and sepsis. II. Clinical aspects. Intensive Care Med 2007; $33: 25-35$.

39. Crouser ED, Julian MW, Huff JE, Mandich DV, Green- Church $\mathrm{KB}$. A proteomic analysis of liver mitochondria during acute endotoxemia. Intensive Care Med 2006; 32: 1252-62.

40. Murch O, Collin M, Hinds CJ, ThiemermannC.Lipoproteins in inflammation and sepsis. I. Basic science. Intensive Care Med 2007; 33:13-24.

41. Abraham NG, Drummond G. CD163-Mediated hemoglobin home uptake activates ( macrophage HO-1, providing and antiinflamatory function. Circ Res 2006; 99:911-4.

42. Otterbein LE, Soares MP, Yamashita K, Bach FH. Hemeoxygenase-1: unleashing the protective properties of heme.Trends Immunol 2003;24:449-55.

43. Berberat PO, Katori M, Kaczmarek E, Anselmo D, Lassman $\mathrm{C}, \mathrm{Ke} \mathrm{B}$ et al. Heavy chain ferritin acts as an antiapoptotic gene that protects livers from ischemia reperfusion injury. FASEB J. 2003; 17:1724-6.

44. Bleesing J, Prada A, Siegel DM, Villanueva J, Olson J, Ilowite NT et al. The diagnostic significance of soluble CD163 and soluble interleukin-2 receptor alpha-chain in macrophage activation syndrome and untreated new-onset systemic juvenile idiopathic arthritis. Arthritis Rheum 2007; 56:96571 .

45. Takala A, Jousela I, Jansson SE, Olkkola KT, Takkunen O, Orpana A et al. Markers of systemic inflammation predicting organ failure in community-acquired septic shock. ClinSci (Lond) 1999; 97: 529-38.

46. Blazar BA, Rodrick ML, O’Mahony JB, Wood JJ, Bessey PQ, Wilmore DW et al. Suppression of natural killer-cell function in humans following thermal and traumatic injury. $J$ ClinImmunol 1986; 6:26-36. 
47. Gupta S., Weitzman S.: Primary and secondary haemophagocyticlymphohistiocytosis: clinical features, pathogenesis and therapy. ClinImmunol 2010; 6: 137-54.

48. Filipovich A.H.: Haemophagocyticlymphohistiocytosis (HLH) and related disorders. Hematology Am. Soc. Hematol. Educ. Program 2009: 127-31.

49. Henter JI, Arico M, Egeler RM, et al. HLH-94: a treatment protocol for haemophagocyticlymphohistiocytosis. HLH study Group of the Histiocyte Society. Med PediatrOncol 1997; 28(5): 342-347.

50. Jordan M.B., Filipovich A.H.: Hematopoietic cell transplantation for haemophagocyticlymphohistiocytosis: a journey of a thousand miles begins with a single (big) step. Bone Marrow Transplant 2008; 42: 433-7.

51. Marsh R.A., Jordan M.B., Filipovich A.H.: Reduced- intensity conditioning haematopoietic cell transplantation for haemophagocyticlymphohistiocytosis: an important step forward. Br J Haematol 2011; 154: 556-63.

52. Maakaroun NR, Moanna A, Jacob JT, Albrecht H. Viral infections associated with haemophagocytic syndrome. Rev Med Virol 2010; 20(2): 93-105.

53. Emmenegger U, Frey U, Reimers A, et al. Hyperferritinemia as indicator for intravenous immunoglobulin treatment in reactive macrophage activation syndromes. Am J Hematol $2001 ; 68: 4-10$

54. Balamuth N.J., Nichols K.E., Paessler M., Taechey D.T.: Use of rituximab in conjunction with immunosuppressive chemotherapy as a novel therapy for Epstein-Barr virusassociated haemophagocyticlymphohistiocytosis. J PediatrHematolOncol 2007; 29: 569-73.

55. Machaczka M., Vaktnäs J., Chiang SC, Bryceson YT. Alemtuzumab treatment for haemophago-cyticlymphohistiocytosis. Nat Rev ClinOncol 2010; 7:10.

56. Strout M.P., Seropian S., Berliner N.: Alemtuzumab as a bridge to allogeneic SCT in atypical haemophago-cyticlymphohistiocytosis. Nat Rev ClinOncol 2010; 7: 415-20.
57. Makay B.,Yilmaz S., Türkyilmaz Z. et al: Etanercept for therapy-resistant macrophage activation syndrome. Pediatr Blood Cancer 2008; 50: 419-21.

58. Sandhu C., Chesney A., Piliotis E. et al: Macrophage activation syndrome after etanercept treatment. J Rheumatol 2007; 34: 241-2.

59. Machaczka M., Nahi H., Karbach H. et al.: Successful treatment of recurrent malignancy-associated haemophagocyticlymphohistiocytosis with a modified HLH94 immunochemotherapy and allogeneic stem cell transplantation. Med Oncol 2011: 29 [Epub ahead of print]. DOI: $10.1007 / \mathrm{s} 12032-011-9963-3$

60. Goi K., Sugita K. and Nakamura M. et al.: Development of acute lymphoblastic leukemia with $\mathrm{t}(4 ; 1)$ in a girl with familial pericentricinv 12. Cancer Genet Cytogenet 1999; 110:124-7.

61. Chang Y.H., Lu P.J., Lu M.Y. et al.: Sequential transplants for respective relapse of Hodgkin disease and HLH: a ( treatment dilemma. J PediatrHematolOncol 2009; 31: 778-81.

62. Ohga S, Kudo K, and Ishii E. et al.: Hematopoietic stem cell transplantation for familial haemophago-cyticlymphohistiocytosis and Epstein-Barr virus-associated haemophagocyticlymphohistiocytosis in Japan. Pediatr Blood Cancer 2010; 54: 299-306.

63. Filipovich A., McClain K., Grom A.: Histiocytic disorders: recent insights into pathophysiology and practical guidelines. Biol. Blood Marrow Transplant 2010; 16 (1): S82-9.

64. Takahashi N, Chubachi A, Kume M, Hatano Y, Komatsuda A, Kawabata Y, et al. A clinical analysis of 52 adult patients with haemophagocytic syndrome: the prognostic significance of the underlying diseases. Int J Hematol 2001; 74(2): 209-13.

65. Hasegawa D, Sano K, KosakaY, Hayakawa A, Nakamura H. A case of haemophagocyticlymphohistiocytosis with prolonged remission after syngenic bone marrow transplantation, Bone Marrow Transplantation 1999; 24: 425-7. 